\title{
Hybrid PV and Wind Energy for Grid Connected System using SEPIC Converter
}

\author{
S. Jensie Anita, Nivedhan, Rajeshwara Prabu, Vysagh
}

\begin{abstract}
A hybrid generator is designed for both wind energy and photovoltaic system (PV) based on permanent magnet synchronous generator to maintain dc link voltage. In this paper, both the sources are connected with grid through a single ended primary inductor converter (SEPIC) and three phase inverter is followed by SEPIC converter. The fuzzy logic controller used to provide gate pulses for the converter and model predictive controller is providing pulses to three phase inverter which tracking the highest power from the wind and $P V$ system. In the $P V$ system the maximum power point tracking (MPPT) method is used to get higher power from the source. This new hybrid system operation is done by both the effective controllers and system steady is achieved. The integrated energy with high efficiency is directed to grid for distribution and the system is verified in Matlab/Simulink and simulation results are given with model.
\end{abstract}

Keywords: DC-DC SEPIC converter, Fuzzy logic controller, model predictive controller, PMSG.

\section{INTRODUCTION}

The major part of the electrical energy is generated by renewable energy sources such as solar systems, wind energy system, tidal energy [1]. The hybrid energy generation combines two sources of energy then it supplied to grid. A PMSG based generator is generating the power to distribution side and it does not require reactive energy support. The permanent magnet synchronous generator is directly driven by turbine of wind [2-6]. The conventional systems have the traditional converter system such as buck converter, boost converter, buck boost converter etc. They have switching losses. Normally the wind and solar energy can be maximized and that can be done only by time of intensity and availability [7]. In the existing hybrid systems they have many converters for every sources and a battery backup storage is used [8]. To obtain high power for utility grid, a complex set of algorithm is used so that the wind and PV source power efficiency as well as power extraction are reduced. To reduce the switching losses of the devices and conduction losses, the power stage conversion should have minimum converters [9-10]. When the switches count is increased, the losses in conduction and power switches will be higher. At the same time, the converter losses in the conversion stage can be compensated while increasing the high amount in its turns of generators but it is caused to expensive [10-12]. The dc link bus voltage is stored

Revised Manuscript Received on December 30, 2019.

S.Jensie Anita, Assitant Professor, Department of Electrical \& Electronics Engineering, Aarupadai Veedu Institute of Technology , Chennai, India.

Nivedhan, Rajeshwara Prabu, Vysagh, UG Students, Department of Electrical \& Electronics Engineering, Aarupadai Veedu Institute of Technology, Chennai, India. in capacitor to maintain the three phase inverter power energy [13-15]. When the system is operating in full load condition the converter efficiency would be around $94 \%$ but to reduce the remaining losses, the proposed system is implemented.

In this paper explains that both PV and wind energy sources together to provide energy to the utility grid. The PMSG generator with wind turbine is generating power in $\mathrm{AC}$ supply. This power is go through under rectification process that means generated AC power is transferred into DC supply. After that rectified energy is passed to DC-DC SEPIC converter which is boost the power from the rectifier. This converter is controlled by fuzzy logic controller to provide gate pulses to the SEPIC converter. The high voltage gain is applied to the DC link capacitor that maintains the voltage which to be inverted.

\section{METHODS AND MATERIALS}

The proposed system consists of wind and PV sources are connected in parallel to provide grid energy supply. The PMSG wind turbine is generating the energy in AC voltage. The generated voltage is converted to DC voltage using rectifier then the converted voltage is enhanced using SEPIC converter. The conventional converters may be such as buck-boost converter, fly back converter and Zeta. Then the photo voltaic source with the MPPT is draw de link capacitor and the DC bus voltage is feeding to three phase inverter for obtaining inverted current. The proposed of wind and PV hybrid system is shown in fig. 1 .

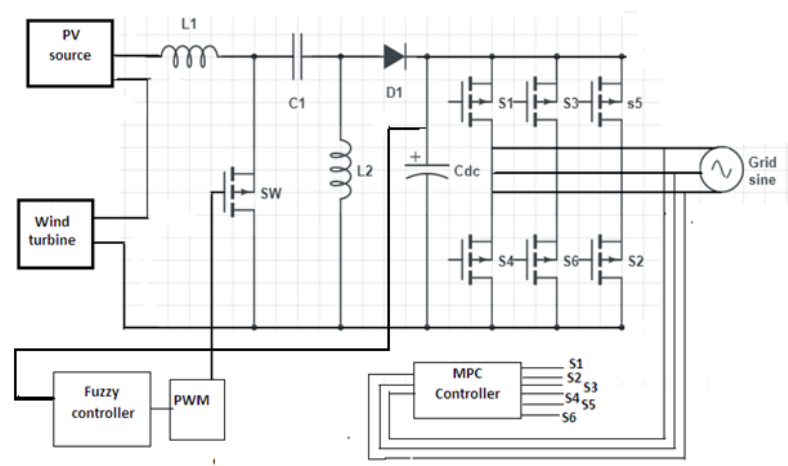

Fig. 1. Proposed Hybrid System

\section{A. Wind and PV}

The PMSG is generating power based on speed of the wind and the applied voltage is varying depends on wind speed. The equivalent circuit of the PMSG is shown in figure 1, the steady state output is obtained.

Then generated voltage is supplied to rectifier for rectification process. In this process Ac voltage is rectified into DC energy and it will direct

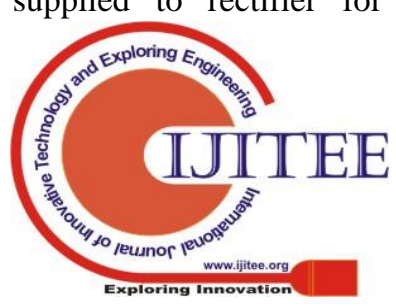


to power conversion stage. In this stage power converter (DC-DC) is used to get high voltage and converter is fed by the rectified voltage $(\mathrm{Vr})$ and rectified current to produce converter voltage ( $\mathrm{Vc}$ ). This converted voltage is called as dc link voltage which is to be maintained. The rectifying current and voltage are given as,

Solar energy is generated and the supply is directed to inverter using the model predictive controller. The solar energy is DC voltage and it is connected with system to improve the performance of the system and gain voltage and high efficiency. The both sources are adding to provide energy to the three phase voltage source inverter (VSI). Then the given voltage to the inverter is converting to the $\mathrm{AC}$ voltage with the improving in voltage. The circuit diagram of the proposed system is shown in fig. 1 .

\section{B. Controllers}

In this proposed system consists of two parts of power stages such as converter and inverter stage of power conversion. In converter stage, a SEPIC converter is performing to attain high voltage and a switch in converter gate pulse is provided by fuzzy logic controller as in fig. 2 . Through the fuzzy controller with pulse width modulation can be obtains an output in accurate. This converter energy is supplying to DC bus.

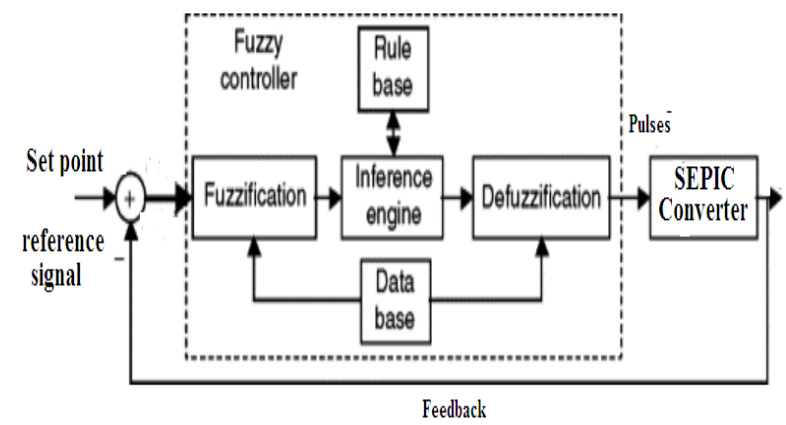

Fig. 2.Proposed fuzzy logic controller

In second part of power stage, a three phase VSI is used to achieve efficient output DC voltage. The MPC block diagram is as shown in fig. 3 by using this controller, the inversion stage is generating AC Voltage from the applied DC input which is fed by DC-DC converter and PV source generation

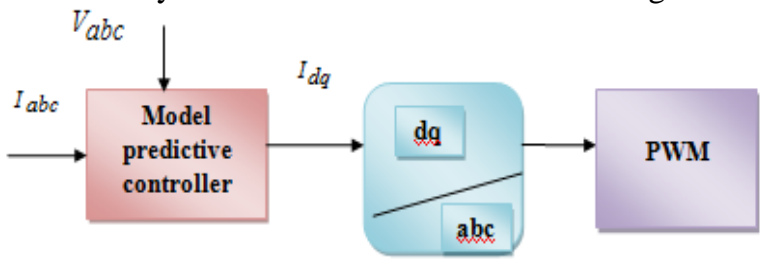

Fig. 3.Model predictive controller process

The model predictive controller is used in grid connected inverter to control voltage and current. The MPC is applied to grid connected inverters due to fast response in dynamic and the constraints as well as nonlinearities of the system can be easily done. It predicts the future behavior of the system. In this system a model predictive controller (MPC) is to provide gate pulses for inverter switching devices and through this voltage and current of grid connected system is controlled. Finally the efficient energy is directed to grid for distribution.

\section{SIMULATION AND RESULTS}

The Simulink model of proposed system is represented in fig.4 the wind source is interfaced corresponding with PV source as a hybrid system and then a sepic converter is increasing the supply to maintain dc link voltage in capacitor. Then three phase inverter is inverting dc link capacitor voltage. Finally three phase filter is reducing the ripples and transfers to grid.

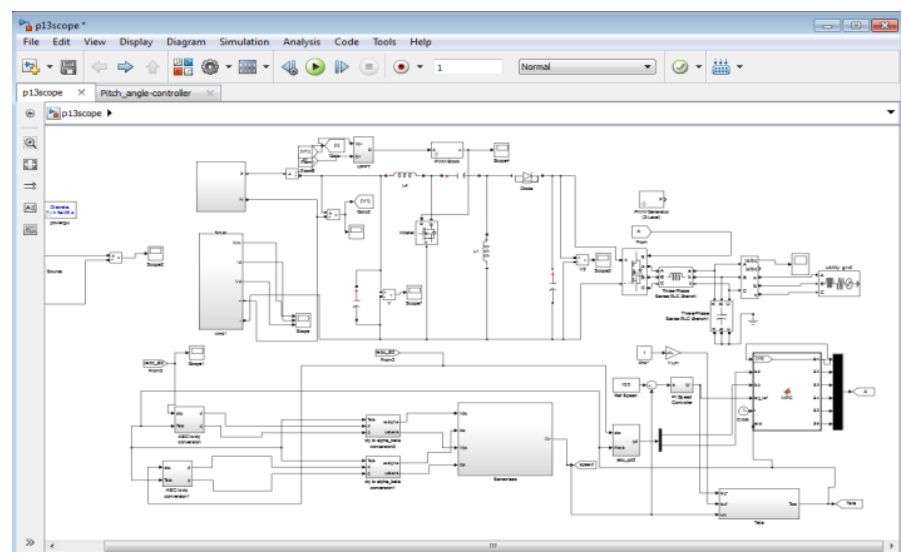

Fig. 4. proposed hybrid system Simulink model

Wind generator is producing $\mathrm{AC}$ voltage which may around $24 \mathrm{v}$. It shows in fig.5. This generated energy is to be rectified and then combined with solar energy. i.e act as hybrid energy source.

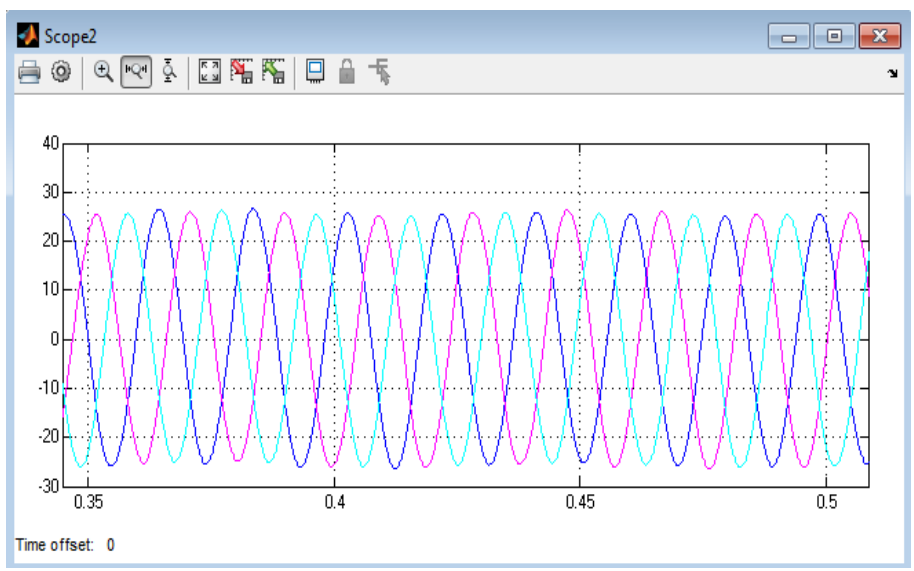

Fig. 5.Output voltage from wind generator

From the PV system, the obtained DC voltage in fig. 6 is $24 \mathrm{~V}$ as below; this energy is fed to the plant with the combination of wind energy that means parallel connection supply. 


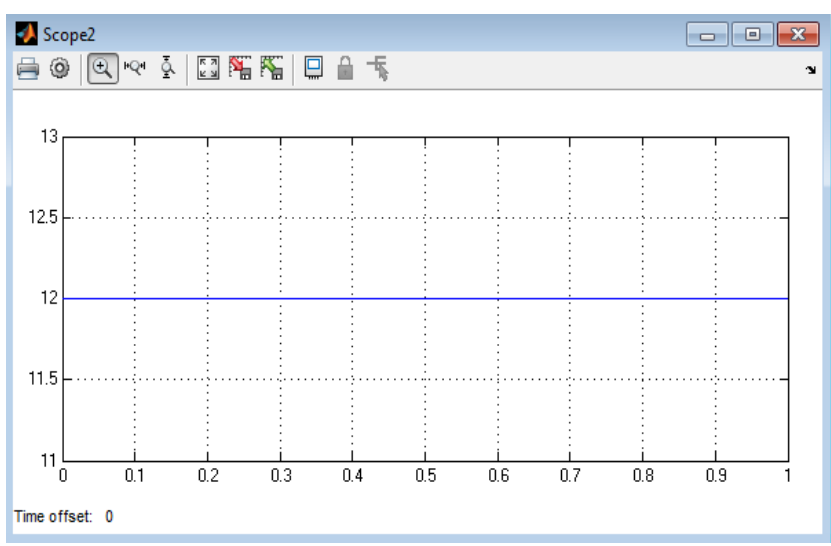

Fig. 6.Output voltage of the PV system

The generated wind energy from PMSG and PV system are together to maintain dc link voltage at the same time, provide the efficient power to grid using various controllers in power stage conversion and the controllers are fuzzy logic controller and model predictive controller. Fig.7. Shows the output grid voltage of proposed system is $600 \mathrm{v}$.

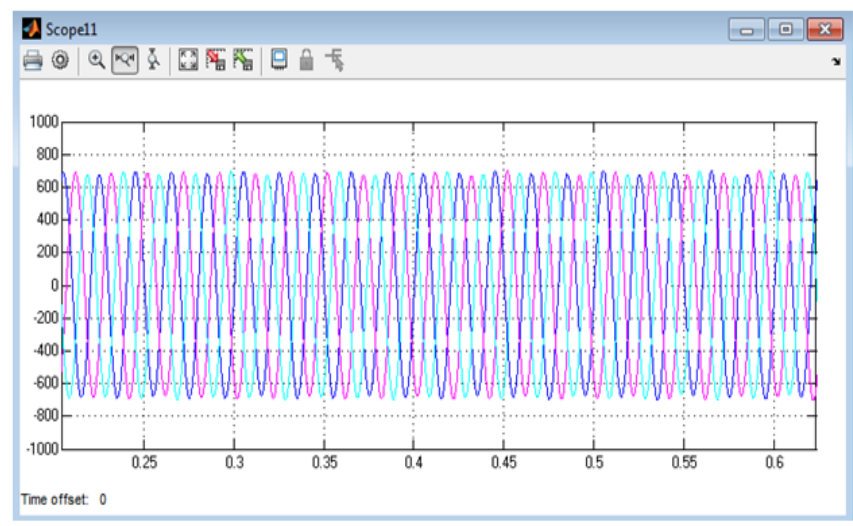

Fig. 7.Output voltage of the grid

The output grid current is shown in fig. 8 which is nearly 50 amps.

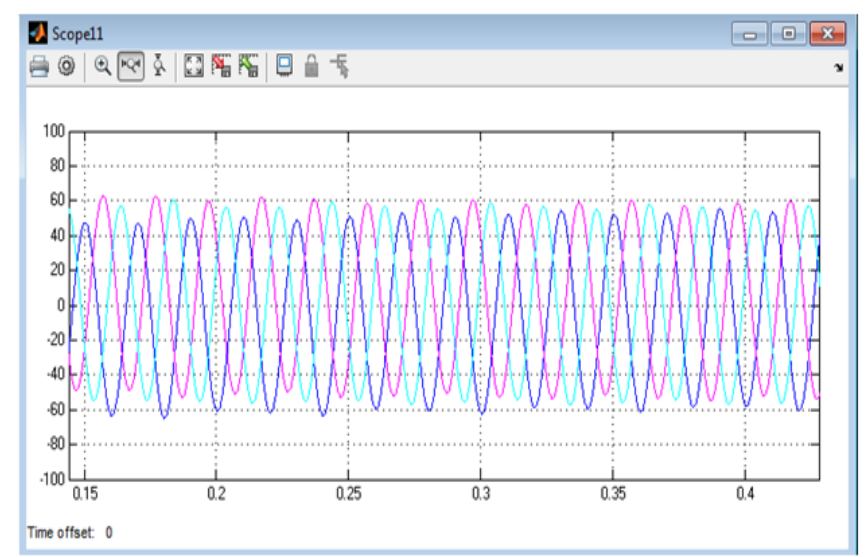

Fig. 8.Grid Output Current

\section{CONCLUSION}

The renewable energies of solar and wind sources are used for constant dc link voltage maintenance and provide improving energy to grid. The model predictive controller is used to providing the gate pulses to the three phase inverter. The grid has the two sources of energy and the sepic converter is used to boost up the applied voltage. The voltage will be given to the grid through the model predictive controller. The both sources are used to provide efficient energy to the grid. The MPPT algorithm of incremental and conductance is used to high energy. The results are verified and the outputs are achieved using Simulink.

\section{REFERENCES}

1. J. Yu , C. Liu, and H. Zhao "Design and Multi-Mode Operation of Double-Stator Toroidal-Winding PM Vernier Machine for Wind-Photovoltaic Hybrid Generation System," IEEE Transactions on Magnetics, 2019.

2. L. Wang, Q. S. Vo, and A. V. Prokhorov, " Stability improvement of a multimachine power system connected with a large-scale hybrid wind-photovoltaic farm using a supercapacitor," IEEE Transactions on Industry Applications, vol. 54, no. 1, pp. 50-60, 2017.

3. S.Siva, "Automatic Solar Tracker," International Journal of MC Square Scientific Research,vol.8, no.1,2016

4. V.B. Manimaran, "Design and Implementation of Solar -Wind Combo for Hybrid Energy Application," International Journal of MC Square Scientific Research, vol.5, No.1, 2013.

5. J. C. Arispe, and A. B. Vasquez, "Wind and PV Farms Integration within Power Systems Using Static and Dynamic Simulations," IEEE Latin America Transactions, vol. 16, no. 1, pp. 148-54, 2018.

6. D. Vidhyalakshmi, and K. Balaji K, "Performance of Bidirectional Converter Based On Grid Application," Indonesian Journal of Electrical Engineering and Computer Science, vol. 12, no. 3, pp. 1203-10, 2018.

7. A. Verma, R. Krishan, and S. Mishra, “ A novel PV inverter control for maximization of wind power penetration," IEEE Transactions on Industry Applications, vol. 54, no. 6, pp. 6364-73, 2018.

8. Z. Ullah, S. Wang, J. Radosavljević,and J. Lai, "A Solution to the Optimal Power Flow Problem Considering WT and PV Generation," IEEE Access, vol. 7, pp. 46763-72. 2019.

9. S. Riverso, S.Mancini, F. Sarzo, and G. Ferrari-Trecate, "Model predictive controllers for reduction of mechanical fatigue in wind farms," IEEE Transactions on Control Systems Technology, vol. 25, no. 2, pp. 535-49, 2016.

10. S. Ebadollahi, and S. Saki, "Wind turbine torque oscillation reduction using soft switching multiple model predictive control based on the gap metric and kalman filter estimator," IEEE Transactions on Industrial Electronics, vol. 65, no. 5, pp. 3890-98, 2017.

11. X. Liu, Y. Zhang, and K. Y. Lee, "Coordinated distributed MPC for load frequency control of power system with wind farms," IEEE Transactions on Industrial Electronics, vol. 64, no. 6, pp.5140-50, 2016.

12. J. S. Solís-Chaves, L. L. Rodrigues, C. M. Rocha-Osorio, A. J. Sguarezi Filho, " A long-range generalized predictive control algorithm for a DFIG based wind energy system," IEEE/CAA Journal of Automatica Sinica, vol. 6, no. 5, pp. 1209-19, 2019.

13. N. Rana, M. Kumar, A. Ghosh, S. Banerjee, "A Novel Interleaved Tri-State Boost Converter With Lower Ripple and Improved Dynamic Response," IEEE Transactions on Industrial Electronics, vol. 65, no. 7, pp. 5456-65, 2017.

14. H. Y. Jung, S. H. Kim, B. Moon, and S. H. Lee, "A new circuit design of two-switch buck-boost converter," IEEE Access. Vol. 6, pp. 47415-23. 2018.

15. L. Callegaro, M. Ciobotaru, D. J. Pagano, E. Turano, and J. E. Fletcher, "A simple smooth transition technique for the noninverting buck-boost converter," IEEE Transactions on Power Electronics, vol. 33, no. 6, pp. 4906-15, 2017.

\section{AUTHORS PROFILE}

S.Jensie Anita, Assistant Professor, Department of Electrical \& Electronics Engineering, AarupadaiVeedu Institute of Technology, Chennai, India.

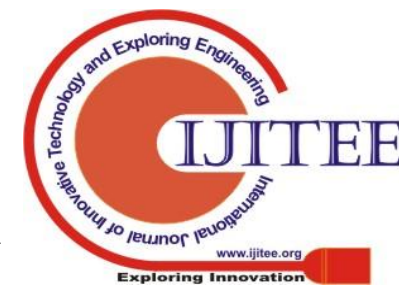


Nivedhan, UG Student, Department of Electrical \& Electronics Engineering, AarupadaiVeedu Institute of Technology, Chennai, India.

Rajeswara Prabu, UG Student, Department of Electrical \& Electronics Engineering, Aarupadai Veedu Institute of Technology, Chennai, India.

Vysagh, UG Student, Department of Electrical \& Electronics Engineering, Aarupadai Veedu Institute of Technology, Chennai, India. 